\title{
Effect of the thermal treatment of carbon-based electrodes on the electrochemical performance of supercapacitors
}

\author{
V. Ruiz ${ }^{*}$, C. Blanco, M. Granda, R. Menéndez and R. Santamaría \\ Instituto Nacional del Carbón (CSIC), Apdo. 73, 33080-Oviedo, Spain
}

\begin{abstract}
This paper reports on the electrochemical performance of carbon-based electrodes subjected to thermal treatment. Changes in texture and chemical composition were evaluated and used to assess the effect of thermal treatment on the electrochemical performance of the resultant supercapacitors. Disc-type electrodes were prepared using polyvinylidene fluoride, PVDF, as binder and a mesophase-derived activated carbon as active material. The carbonization of the electrodes under inert atmosphere $\left(\mathrm{N}_{2}\right.$-flow) at 600 and $1000{ }^{\circ} \mathrm{C}$ leads to the decomposition of the polymer making it possible to recover most of the surface area that is blocked by the polymer. The carbonized electrodes were tested as electrodes in supercapacitors, with the result that lower specific capacitance values were obtained than with the "un-treated" electrodes. This was attributed to the formation of constrictions at the entrance of the porous network as a consequence of the polymeric decomposition. Furthermore, electrical conductivity, power density and long-cycling performance showed a significant improvement as a result of the carbonization procedure.
\end{abstract}

Keywords: activated carbon; supercapacitors; binder; surface area; polymer decomposition.

*Corresponding author: vanesa@incar.csic.es; Tel. + 349851190 90; Fax: + 34985297662 


\section{1.- INTRODUCTION}

Supercapacitors fill the gap existing between batteries and conventional capacitors as they are able to store and deliver energy at high rates. Of the types of active materials that can be employed as electrodes in supercapacitors, carbon materials are the most commonly used because of their relatively low cost, high surface area, large capacitance values and chemical and temperature stability. In carbon-based supercapacitors, the electrical charge is stored in the interface between the electrode and the electrolyte. The electrode is composed of a current collector that is in contact with the active material. The collector must be chemically stable in the electrolyte and in the potential window used. The active material is usually an activated carbon in powdered form. In order to bind the carbonaceous particles into compact electrodes (e.g. disc-type electrodes, film coatings) it is necessary to use a binder (generally polymeric, e.g. PVDF, PVDC, PTFE). These electrodes require some mechanical strength so that they can be handled easily and they also need to have good electrical properties (e.g. electrical conductivity). However, the addition of the polymer has been widely reported to have a negative influence on the properties of the active material in the form of a reduction of surface area [1]-[2] and an increase in electrical resistivity [3]-[4]. Thus, an excessive amount of binder will increase the resistance of the electrode, giving rise to the ESR of the capacitor [5], and lower specific capacitance values due to a lack of accessibility to the porous network [1]. It follows, therefore, that the smaller the amount of polymer used, the better provided that the mechanical requirements mentioned above are fulfilled. However, in large-scale preparations this effect might be less pronounced than in a lab-scale as the preparation techniques are optimized for both the material and the polymer.

This paper reports on the use of heat treatment to transform the polymer used to conform the electrodes and on the consequent decomposition of the polymer. The heat treatment is expected to increase the surface area of the electrodes and, consequently, the porosity 
accessible to the electrolyte when acting as electrodes in supercapacitors. Electrical conductivity is also expected to improve because the polymer is transformed into carbon. Carbonization temperatures of 600 and $1000{ }^{\circ} \mathrm{C}$ were selected based on thermogravimetric studies carried out on electrodes and on thermal-programmed desorption experiments (TPD). The electrochemical performance of the electrodes subjected to heat treatment was evaluated taking into account both the textural and chemical modifications experienced by the active material. A recent study by the authors demonstrated the effect of thermal treatment on the same activated carbon as that used in the present work [6].

\section{2.- EXPERIMENTAL}

\section{1.- Preparation of the active materials and of electrodes}

Naphthalene-derived mesophase pitch AR24 was chemically activated using (3:1) KOH to carbon mass ratio at $700{ }^{\circ} \mathrm{C}$ for one hour under nitrogen flow $\left(62 \mathrm{~mL} \mathrm{~min}^{-1}\right)$. The resultant material was neutralized with $1 \mathrm{M} \mathrm{HCl}$ and then washed with distilled water until neutral $\mathrm{pH}$. Finally, the activated carbon was dried at $110{ }^{\circ} \mathrm{C}$ in a vacuum oven for $24 \mathrm{~h}$. The resultant active material was labelled A7.

In order to study the changes that occurred in the activated carbon itself, the material A7 was thermally treated at 600 and $1000{ }^{\circ} \mathrm{C}$ for one hour at a heating rate of $2.5^{\circ} \mathrm{C} \mathrm{min}^{-1}$ under a flow of nitrogen. The carbonized activated carbons were labelled A7-600 and A7-1000.

Disc-type electrodes were prepared by pressing a mixture of the active material (A7, A7-600 or A7-1000), 90 wt. \%, and polyvinylidene fluoride, 10 wt. \%. These two components were mixed in an agate mortar without using any solvent. Each electrode was about $30 \mathrm{mg}$ in weight and $400 \mu \mathrm{m}$ in thickness. The resultant electrodes were labelled E-A7, E-A7-600 or EA7-1000 depending on the active material used for their fabrication. These electrodes are referred to as "un-treated" electrodes throughout this work. 
Some of the E-A7 electrodes were thermally treated in a horizontal furnace at 600 and $1000{ }^{\circ} \mathrm{C}$ under the same conditions as the activated carbon. The resultant carbonized electrodes (CE) were labelled CE-600 and CE-1000, where the number stands for the temperature of carbonization used.

\section{2.- Characterization of materials}

The polymer was subjected to thermogravimetric analysis in nitrogen in order to evaluate the residue of polymer left after the carbonization step. Around $15 \mathrm{mg}$ of PVDF was used for the TGA experiments at a heating rate of $10^{\circ} \mathrm{C} \min ^{-1}$ up to $1000^{\circ} \mathrm{C}$.

The oxygen content of the activated carbons (A7, A7-600 and A7-1000) was determined by direct determination using a LECO-TF-900 furnace coupled to a LECO-CHNS-932 microanalyser.

The amount and type of oxygenated functionalities were determined by temperatureprogrammed decomposition (TPD) under inert atmosphere (He). About $150 \mathrm{mg}$ of sample was placed in a U-shaped quartz cell and treated at $1000{ }^{\circ} \mathrm{C}$ at an increasing temperature of $10{ }^{\circ} \mathrm{C} \mathrm{min}{ }^{-1}$. The decomposition products $\left(\mathrm{CO}\right.$ and $\left.\mathrm{CO}_{2}\right)$ were identified using an on-line mass spectrometer.

The physical adsorption of nitrogen at $77 \mathrm{~K}$ was carried out in order to characterize the porous texture of the activated carbons and carbon-based electrodes. Isotherms were performed in an ASAP 2020 Micromeritics volumetric system using around $50 \mathrm{mg}$ of sample for each measurement. The apparent specific surface area was determined from the $\mathrm{N}_{2}$ adsorption isotherm using the BET equation. The total micropore volume $\left(\mathrm{V}_{\mathrm{N} 2}\right)$ was calculated by applying the Dubinin-Radushkevich (DR) equation to the $\mathrm{N}_{2}$ isotherm. The total pore volume was obtained from the $\mathrm{N}_{2}$ adsorption at $\mathrm{P} / \mathrm{P}^{0}=0.99$ and the volume of mesopores was calculated by subtracting the total micropore volume $\left(\mathrm{V}_{\mathrm{N} 2}\right)$ from the total 
pore volume. As the total polymer contribution to the adsorption of nitrogen may be considered negligible, the amount of PVDF present in the electrodes was ignored in the calculation of the volume of gas nitrogen adsorbed.

The microporosity of the electrodes was further characterized by measuring the enthalpy of immersion of the samples into liquids of different critical dimensions [7]. Measurements were carried out at $20{ }^{\circ} \mathrm{C}$ using dichloromethane $(0,33 \mathrm{~nm})$ and tri-2,4-xylilphosphate, TXP, $(1,5 \mathrm{~nm})$. For each experiment, around $100 \mathrm{mg}$ of sample was required.

The electrical conductivity of the electrodes was determined using a four-point probe method [8]. Measurements were performed at various pressures up to $40 \mathrm{MPa}$. These were calculated using a load cell for high accuracy.

\section{3.- Electrochemical Behaviour}

The electrochemical performance of the samples was studied using the "un-treated" electrodes as well as the carbonized discs (CE-600 and CE-1000). Two electrode capacitors consisting of a glassy fibrous separator and gold current collectors in a Swagelok ${ }^{\circledR}$ cell were built. Tests were performed in $1 \mathrm{M} \mathrm{H}_{2} \mathrm{SO}_{4}$. Galvanostatic cycling of the supercapacitors was carried out in the voltage window between 0 and $1 \mathrm{~V}$ at current densities of 0.88 to $88 \mathrm{~mA} \mathrm{~cm}^{-2}\left(40-4,000 \mathrm{~mA} \mathrm{~g}^{-1}\right)$ using a Biologic VMP multichannel potenciostat. The capacitance of the system was obtained applying the following equation: $\mathrm{C}_{\text {capacitor }}(\mathrm{F})=\mathrm{I} /(\mathrm{dV} / \mathrm{dt})$ (avoiding the ohmic drop). In a two-electrode system, the lower capacitance value of the two electrodes connected in series will give the total capacitance in accordance with the formula: $1 / \mathrm{C}_{\text {capacitor }}=1 / \mathrm{C}_{1}+1 / \mathrm{C}_{2}$. Assuming that $\mathrm{C}_{1}=\mathrm{C}_{2}$ the specific capacitance of the electrode, $\mathrm{C}\left(\mathrm{F} \mathrm{g}^{-1}\right)$, can be obtained from the expression: $\mathrm{C}=2 \mathrm{C}_{\text {capacitor }} / \mathrm{m}$ ( $\mathrm{m}$ is the mass of activated carbon in the lightest electrode). Voltammetry experiments were carried out at 1 and $50 \mathrm{mV} \mathrm{s}^{-1}$. The equivalent series resistance (ESR) was calculated by 
dividing the ohmic drop by the current intensity, $\operatorname{ESR}(\Omega)=\operatorname{IR}_{\text {drop }}(\mathrm{V}) / \mathrm{I}(\mathrm{A})$. Electrochemical impedance spectroscopy measurements were also carried out in the frequency range of $1 \mathrm{mHz}-100 \mathrm{kHz}$ with an AC amplitude of $\pm 10 \mathrm{mV}$. All impedance measurements were performed at OCV (completely discharged cell).

Long-term cycling was performed at a current density of $10 \mathrm{~mA}$ (equivalent to $9 \mathrm{~mA} \mathrm{~cm}{ }^{-2}$ in the configuration used) in the voltage window $0-1 \mathrm{~V}$. The effect of cycling on the specific capacitance values was assessed.

\section{3.- RESULTS AND DISCUSSION}

\section{1.- Activated carbons}

Before studying the changes that have occurred in the carbon-based electrodes, it is important to assess any modifications in the powdered activated carbon when it is subjected to the same thermal treatment.

Regarding chemical changes, when the activated carbon A7 is heat treated at $600{ }^{\circ} \mathrm{C}$ there is a substantial reduction in the oxygen content (from 3.5 to $1.5 \mathrm{wt} \%$, see Table 1). The TPD experiments show that most of the oxygen removed at this temperature corresponds to $\mathrm{CO}_{2}$ evolving groups (carboxylic acids, lactones anhydrides [9]) and the oxygen content of most of the CO-evolving groups remain stable. When the temperature is increased to $1000{ }^{\circ} \mathrm{C}$, most of the oxygenated functionalities are eliminated.

As might be expected, thermal treatment also leads to some unavoidable textural modifications. When the activated carbon $\mathrm{A} 7$ is treated at $600{ }^{\circ} \mathrm{C}$ there is a slight reduction in the capacity to adsorb the nitrogen of the corresponding sample (A7-600). This leads to a reduction in the total pore volume (from 0.85 to $0.80 \mathrm{~cm}^{3} \mathrm{~g}^{-1}$ ), and in the microporous surface area, $\mathrm{S}_{\text {mic }}$, (from $15311407 \mathrm{~m}^{2} \mathrm{~g}^{-1}$, an $8 \%$ reduction). An explanation for the decision to use Smic instead of BET surface area can be found elsewhere [6]. However, when the 
temperature is increased to $1000{ }^{\circ} \mathrm{C}$ the texture of $\mathrm{A} 7$ changes more significantly as a result of textural reorganization which typically occurs during the treatment of carbon materials at high temperature [10]. At this temperature the total pore volume decreases from 0.85 to 0.66 $\mathrm{cm}^{3} \mathrm{~g}^{-1}$ while the $\mathrm{S}_{\text {mic }}$ decreases to $1318 \mathrm{~m}^{2} \mathrm{~g}^{-1}$ (a $14 \%$ reduction compared to A7). The average pore size is also considerably reduced.

\section{2.- Electrodes}

Thermogravimetric analysis carried out on the PVDF (Figure 1) shows that a well-defined weight loss occurs at $480{ }^{\circ} \mathrm{C}$, leaving a residue of $28 \%$ of the initial weight. When heated up to $1000{ }^{\circ} \mathrm{C}$ the polymer leaves a residue of only $20 \mathrm{wt} . \%$.

The temperatures of electrode carbonization $\left(600\right.$ and $\left.1000{ }^{\circ} \mathrm{C}\right)$ were selected on the basis of the TGA experiments and the characterization carried out on the raw and thermally treated activated carbon A7 (Table 1). At these temperatures most of the binder has been removed although the electrodes continue to be manageable. However, each carbonized electrode shows a distinct chemistry; at $600{ }^{\circ} \mathrm{C}$ most of the groups that evolve as $\mathrm{CO}_{2}$ have been removed whereas the majority of the CO-evolving groups are still present. At $1000^{\circ} \mathrm{C}$ all of the oxygenated-functional groups have been eliminated.

The nitrogen adsorption isotherms obtained for the activated carbon (A7), the "un-treated" electrode (E-A7) and the carbonized electrodes (CE-600 and CE-1000) are displayed in Figure 2. The shape of the isotherms (type I) indicates the microporous character of both the activated carbon and the electrodes. The textural parameters obtained from the isotherm are listed in Table 2. The total pore volume for the activated carbon $\left(0.85 \mathrm{~cm}^{3} \mathrm{~g}^{-1}\right)$ has clearly been reduced after the addition of the polymer (to $0.71 \mathrm{~cm}^{3} \mathrm{~g}^{-1}$ ). The micropore volume estimated from the DR equation has also been reduced (from $0.72 \mathrm{~cm}^{3} \mathrm{~g}^{-1}$ for $\mathrm{A} 7$ to $0.61 \mathrm{~cm}^{3} \mathrm{~g}^{-1}$ for EA7), as have the microporous surface area and the BET surface area. There is, therefore, a 
significant blockage of the porosity of the active material when an electrode is conformed with a binder. The electrode is subjected to thermal treatment so as to promote the subsequent decomposition of the polymer and thereby unblock some of the porosity. After the heat treatment of the electrode at $600{ }^{\circ} \mathrm{C}$, there is an increase in the total pore volume (from $0.71 \mathrm{~cm}^{3} \mathrm{~g}^{-1}$ to $0.85 \mathrm{~cm}^{3} \mathrm{~g}^{-1}$ in E-A7 and CE-600, respectively), as well as in the other textural parameters which reach similar values to those of A7. This shows that at $600{ }^{\circ} \mathrm{C}$ it is possible to remove most of the polymer present in the electrode and thereby release the surface area blocked during the elaboration of the electrodes. As much as $25 \%$ of the microporous surface area of the electrode can be recovered (from the data displayed in Table 2).

After the electrodes E-A7 are heat treated at $1000{ }^{\circ} \mathrm{C}$ their capacity to adsorb nitrogen is reduced compared to the capacitance of CE-600. What is more, they undergo reduction in average pore diameter, from $1.03 \mathrm{~nm}$ to $0.87 \mathrm{~nm}$ and at this temperature, in addition to the removal of the polymeric binder, there is a more pronounced textural reorganization compared to CE-600. The microporous surface area also increased after the carbonization procedure, from $1174 \mathrm{~m}^{2} \mathrm{~g}^{-1}$ up to $1467 \mathrm{~m}^{2} \mathrm{~g}^{-1}$ (an increase of $20 \%$ ), which is concordant with the presence of pores of a smaller size.

The thermal treatment of the electrodes also leads to positive modifications in their electrical conductivity. Figure 3 shows the conductivity values obtained for the "un-treated" electrode and the carbonized ones versus the pressure applied. It can be observed that, when the temperature of the treatment is increased, there is an increase in the electrical conductivity of the electrodes. This increase is moderate at $600{ }^{\circ} \mathrm{C}$ but quite pronounced at $1000{ }^{\circ} \mathrm{C}$ and is the result of several effects: improved contact between the carbonaceous particles, the greater conductivity of residue that leaves the polymer compared to the PVDF, and the enhanced conductivity between the carbonaceous particles due to the reordering of the structure. 
Additionally, the removal of functional groups has a positive effect in that it favours the transport of electrons.

\section{3.- Electrochemical characteristics}

\subsection{1.- Performance of the "un-treated" electrodes}

In order to clarify the line of reasoning applied to the carbonized electrodes, the non carbonized electrodes prepared with A7 (E-A7) and the carbonized powders A7-600 (E-A7$600)$ and A7-1000 (E-A7-1000) were analyzed in a two-electrode cell using 1M sulphuric acid as electrolyte. A brief summary of the results is presented in Table 1 which shows the high specific capacitance values provided by E-A7 $\left(309 \mathrm{~F} \mathrm{~g}^{-1}\right)$. By contrast the electrodes EA7-600 provide $8 \%$ fewer specific capacitance values than E-A7, which is coincident with the reduction in microporous surface area (Table 1). It can be concluded, therefore, that the oxygenated-functional groups removed at $600{ }^{\circ} \mathrm{C}\left(\mathrm{CO}_{2}\right.$-evolving groups, deduced from the TPD-experiments) do not have a significant effect on the specific capacitance values. The electrodes E-A7-1000 lead to additional conclusions. The specific capacitance values provided by E-A7-1000 (196 $\left.\mathrm{F} \mathrm{g}^{-1}\right)$ are $36 \%$ lower than the values obtained for E-A7, whereas the reduction in $\mathrm{S}_{\text {mic }}$ is only by $14 \%$. Consequently, the oxygenated functional groups that are removed when the heat treatment is increased to $1000{ }^{\circ} \mathrm{C}$ (CO-evolving groups) can be attributed to reversible redox reactions $[11,12]$. At $1000{ }^{\circ} \mathrm{C}$ densification of the activated carbon together with the removal of all pseudocapacitative effects lead to low values of capacitance, compared to E-A7. A more detailed description of these results can be found elsewhere [6]. 


\subsection{2.- Performance of the carbonized electrodes}

Figure 4 shows the influence of the current density on the specific capacitance values as determined by galvanostatic charge-discharge measurements. Here it can be clearly seen that, contrary to the expected increase in capacitance due to the recovery of surface area, the experimental capacitance values obtained for the carbonized electrodes are lower than the ones obtained for E-A7. The same figure shows the estimated capacitance values for the carbonized electrodes based on the increase in microporous surface area calculated from the nitrogen isotherms (an increase of $25 \%$ for CE-600 and of $20 \%$ for CE-1000 compared to the $S_{\text {mic }}$ calculated for E-A7, in Table 2). The capacitance values estimated were obtained from the $\mathrm{S}_{\text {mic }}$ modifications as this has already been proved to be the most suitable textural parameter for explaining the electrochemical data [1],[6].

Taking into account the increase in surface area after the heat treatment of E-A7 at $600{ }^{\circ} \mathrm{C}$ (see Table 1) and the lack of electrochemical activity of the $\mathrm{CO}_{2}$-groups removed at this temperature, it seems reasonable to assume that other factors, apart from the texture of the materials, are responsible for the low experimentally observed capacitance values.

The results provided by immersion calorimetry may serve to shed some light on the matter. Table 3 shows the heats of immersion obtained for A7, the electrode E-A7 and the carbonized electrodes in dichloromethane and tri-2,4-xylilphosphate. When binder is added to the activated carbon there is a reduction in the heat of immersion provided by both liquids, which is consistent with pore blockage deduced from the $\mathrm{N}_{2}$-isotherms at $77 \mathrm{~K}$. This reduction is more evident for the TXP (from $132 \mathrm{~J} \mathrm{~g}^{-1}$ for A7, down to $82 \mathrm{~J} \mathrm{~g}^{-1}$ for E-A7), than for the dichloromethane due to its larger size, indicating that the TXP finds it more difficult to gain access to the pores.

When the electrodes are carbonized at $600{ }^{\circ} \mathrm{C}$ there is a slight increase in the heat of immersion obtained for $\mathrm{CH}_{2} \mathrm{Cl}_{2}$ (from $197 \mathrm{~J} \mathrm{~g}^{-1}$ in E-A7 to $206 \mathrm{~J} \mathrm{~g}^{-1}$ in CE-600), which is 
further evidence that the surface area increases after the degradation of the polymer. However, when TXP is used the enthalpy of immersion decreases drastically (from $82 \mathrm{~J} \mathrm{~g}^{-1}$ in E-A7 to $43 \mathrm{~J} \mathrm{~g}^{-1}$ in CE-600). This seems to indicate the creation of some kind of hindrance to the larger molecules within the porous network, probably due to the microporous nature of the carbon residue formed after the decomposition of the polymer. Even though the electrode CE-600 has a higher surface area (as determined by gas adsorption) than E-A7, TXP is unable to access it completely. This may explain the reduction in specific capacitance values observed after the electrodes are treated at $600{ }^{\circ} \mathrm{C}$, since the aqueous electrolyte which has a greater volume than $\mathrm{N}_{2}$ or $\mathrm{CH}_{2} \mathrm{Cl}_{2}$, finds it more difficult to gain access.

The situation after treatment at $1000{ }^{\circ} \mathrm{C}$ is even more complex. Theoretically an improved electrochemical performance might be expected also for CE-1000 as its microporous surface area undergoes a $20 \%$ increase compared to E-A7 (see Table 2). At this temperature, it should be noted that all the oxygenated-functional groups have already been completely removed as mentioned before. This has a considerable effect on the performance of the material, due to the loss of pseudocapacitive phenomena, as was previously stated ([6],[13]). Furthermore, as restrictions to the access of the porosity were shown to be present in CE-600, immersion calorimetry experiments were carried out for CE-1000 in order to check for the presence of constrictions. The results obtained are summarized in Table 3. After the electrode was treated at $1000{ }^{\circ} \mathrm{C}$ there was a slight reduction in the heat of immersion in $\mathrm{CH}_{2} \mathrm{Cl}_{2}$ (from $197 \mathrm{~J} \mathrm{~g}^{-1}$ in E-A7 to $178 \mathrm{~J} \mathrm{~g}^{-1} \mathrm{CE}-1000$ ) and a very significant decrease in TXP (from 82 to $14 \mathrm{~J} \mathrm{~g}^{-1}$ ) whereas the nitrogen isotherms showed that their textural parameters had hardly experienced any change. This discrepancy indicates that the access of the organic liquids is restricted firstly due to the presence of constrictions and secondly due to the reduction in the average pore size (Table 2) creating additional constrictions for the electrolyte at the pore entrances. 
It can be concluded that, although the thermal treatment of electrodes leads to a recovery of the surface area blocked by the polymer, the unexpected appearance of constrictions at the entrance of the porous network has a negative effect which cannot be compensated by an increase in the surface area of the electrodes. Thus it may be beneficial to use a polymer that decomposes, leaving behind a macroporous carbon residue that would allow the electrolyte to access the entire surface area.

The performance of the electrodes was also evaluated by means of cyclic voltametry (Figure 5). It can be observed that the specific capacitance values follow the same tendency as the one observed in the galvanostatic experiments. For all the electrodes, voltammograms exhibit a rectangular shape which is typical of electrical double layer capacitors [14]. As the sweep rate increases to $50 \mathrm{mV} \mathrm{s}^{-1}$, the rectangular shape becomes slightly distorted. This explains why it takes the current longer to reach a horizontal value close to the reversal of the potential sweep [15], which is less evident when the temperature of carbonization increases. The presence of oxygenated-functional groups may retard the mobility of ions, giving rise to ohmic resistance. Moreover, these functional groups may act as polar sites and the adsorbed molecules of water make it more difficult for the electrolyte to diffuse $[16,17]$. The presence of faradaic reactions may also play a role in the distortion of the voltammograms [18].

The results obtained by impedance spectroscopy are presented in the Figure 6 . At high frequencies, the imaginary part of the impedance tends towards zero and the resistance measured being related to the ionic resistance of the electrolyte. In the range of medium-high frequencies a semicircle can be observed for E-A7. This semicircle is associated with the resistance that arises from the porous structure of the electrode [19], with the contact electrode/current collector [20], or even with the occurrence of faradaic phenomena [21]. The amplitude of the loop changes in accordance with the nature of the active material. When the electrodes are heat treated the loop disappears, indicating that there is an improvement in the 
global resistance of the cell due to the improvement in the electrical conductivity of the active materials and to the removal of the faradaic effects. This is also reflected in the reduction of the ESR: $2.3,1.7$ and $1 \Omega \mathrm{cm}^{2}$ for E-A7, CE-600 and CE-1000, respectively.

At low frequencies, the imaginary part of the impedance increases sharply in all cases, which corresponds to the capacitive behaviour of the material. At this point, the impedance should be a vertical line parallel to the imaginary axis. Figure $6 . \mathrm{b}$ shows the dependence of the capacitance values on frequency. In this representation it can be defined two parts. In the range of low frequencies the values of capacitance are quite steady with frequency but in the high frequencies region, the capacitance values decrease sharply with frequency. In the high frequency range, there are no significant differences between samples as there is no time for ions access the whole porosity. However, in the low frequency range some differences can be observed. Samples become less frequency-dependent when the temperature of the treatment is increased. This is attributed to the absence of functional groups in the carbonized materials. In such conditions the mobility of ions is favoured and the process of charging the capacitor becomes less kinetic dependent.

From the results discussed above it can be affirmed that thermal treatment causes a decrease both in capacitance and resistance. Consequently, although less energy can be stored in the electrodes, their power increases. It should also be pointed out that the electrodes carbonized at $600{ }^{\circ} \mathrm{C}$ combine both high power and energy densities $\left(10 \mathrm{Wh} \mathrm{Kg}^{-1}\right.$ and $\left.12,000 \mathrm{~W} \mathrm{Kg}^{-1}\right)$, because they maintain their high specific capacitance values together with an improved electrical conductivity unlike E-A7.

During the experiments a new pair of electrodes was subjected to long term cycling. The loss of specific capacitance values during long-term cycling for E-A7 and CE-1000 is represented in Figure 7. Both these electrodes show high cyclability, with quite stable capacitance values. For E-A7 a total loss of about $15 \%$ of the initial capacitance occurred. The situation was 
even better for CE-1000, which only showed a loss of $4 \%$ after 6,000 cycles. These results are in accordance with the smaller amount of oxygen functionalities present in the treated electrode compared to the "un-treated" one. The CE-1000 electrodes maintain their initial electrochemical properties as they are less prone to the oxidation that takes place in cycling.

\section{4.- CONCLUSIONS}

This paper reports on the results obtained from the thermal treatment of carbon-based electrodes prepared with a binder, the purpose of such treatment being to recover the surface area of the carbon after the decomposition of the polymer.

Although they had more surface area than the starting electrodes, the specific capacitance values obtained were lower after the electrodes were treated at 600 and $1000{ }^{\circ} \mathrm{C}$. At $600{ }^{\circ} \mathrm{C}$ the main reason for this behaviour was the formation of physical constrictions at the entrance of the porous network which make it more difficult for the electrolyte to gain access. Consequently the capacitance values provided by the carbonized electrodes are lower than for the "un-treated" electrode. For the electrodes treated at $1000{ }^{\circ} \mathrm{C}$ constrictions also occurred, but in this case the removal of the surface functional groups had an additional negative impact on the performance of the treated electrodes (due to the elimination of the pseudocapacitance associated with them).

By contrast, heat treatment improves the electrical conductivity of the electrodes, which is reflected in an improved ESR, a more efficient power delivery and exceptional long-duration cycling. 


\section{REFERENCES}

[1] V. Ruiz, C. Blanco, M. Granda, R. Menéndez, R. Santamaría, Journal of Applied Electrochemistry 37 (2007) 717.

[2] S. Y. Yoon, J. Lee, T. Hyeon, S. M. Oh, Journal of the Electrochemical Society 147 (7) (2000) 2507.

[3] T. C. Weng, H. Teng, Journal of the Electrochemical Society 148 (2001) A368

[4] J. Gamby, P. L. Taberna, P. Simon, J. F. Fauvarque, M. Chesneau, Journal of Power Sources $101(2001) 109$.

[5] L. Bonnefoi, P. Simon, J. F. Fauvarque, C. Sarrazin, A. Dugast, Journal of Power Sources 79 (1999) 37.

[6] V. Ruiz, C. Blanco, E. Raymundo-Piñero, V. Khomenko, F. Béguin, R. Santamaría Electrochimica Acta 52 (2007) 4969.

[7] J. Silvestre-Albero, C. Gómez de Salazar, A. Sepúlveda-Escribano, F. RodríguezReinoso, Journal of Colloids and Surfaces. A: Physicochemical and Engineering Aspects 187 (2001) 151.

[8] L. J. Van der Pauw, Philips Tech. Rev. 20 (1958) 220.

[9] G. Tremblay, F. J. Vastola, P. L. Walter, Carbon 16 (1978) 35.

[10] I. Martín-Gullón, J. P. Marco-Lozar, D. Cazorla-Amorós, A. Linares-Solano. Extended Abstracts, Carbon Conference, Oviedo, 2003. 
[11] M.J. Bleda-Martínez, J.A. Maciá-Agullón, D. Lozano-Castelló, E. Morallón,

D. Cazorla-Amorós, A. Linares-Solano, Carbon 43 (2005) 2677.

[12] Y.-R. Nian, H. Teng, J. Electrochem. Soc. 149 (2002) A1008.

[13] C. H. Kim, S. I. Pyun, Journal of the Electrochemical Society, 149 (2002) A93.

[14] E. Frackowiak, F. Béguin, Carbon 39 (2001) 937.

[15] C. T. Hsieh, H. Teng, Carbon 40 (2002) 667.

[16] S. Biniak, A. Swiatkoski, M. Pakula, L.R. Radovic, (Eds.), Chemistry and physics of carbon, vol. 27, Marcel Dekker, New York, (2001) 125.

[17] M. Zuleta, P. Björnbom, A. Lundblad, Journal of The Electrochemical Society, 152 (2) (2005) A270.

[18] L. G. Austin, E. G. Gagnon, Journal of the Electrochemical Society 120 (1973) 251.

[19] P. Fievet, M. Mullet, J. Pagetti, Journal of Membrane Science 149 (1998) 143.

[20] Y. R. Nian, H. S. Teng, Journal of Electroanalytical Chemistry 540 (2003) 119.

[21] D. Y. Qu, Journal of Power Sources 109 (2002) 403. 


\section{Acknowledgements}

This work was undertaken with financial support from the MEC (project MAT2007-61467) and FICYT (project IB05-086-C1). V. Ruiz acknowledges a predoctoral research grant provided by FICYT. 


\section{FIGURE CAPTIONS}

Figure 1.- Thermogravimetric analysis for $\operatorname{PVDF}\left(10^{\circ} \mathrm{C} \mathrm{min}^{-1}\right.$ in nitrogen atmosphere $)$

Figure 2.- $\mathrm{N}_{2}$ adsorption/desorption isotherms of the activated carbon (A7), the "un-treated" electrode (E-A7) and the carbonized electrodes (CE-600 and CE-1000).

Figure 3.- Electrical conductivity results for the electrodes.

Figure 4.- Variation in the experimental and estimated specific capacitance values with current density in $1 \mathrm{M} \mathrm{H}_{2} \mathrm{SO}_{4}$. Voltage window $1 \mathrm{~V}$.

Figure 5.- Cyclic voltammetry performed at: a) $1 \mathrm{mV} \mathrm{s}^{-1}$ and b) $50 \mathrm{mV} \mathrm{s}^{-1}$

Figure 6.- a) Complex-plane impedance plots and b) dependence of the capacitance values on frequency

Figure 7.- Long-term cycling for the "un-treated" electrode (E-A7) and the carbonized electrode at $1000^{\circ} \mathrm{C}(\mathrm{CE}-1000)$ at an $8,8 \mathrm{~mA} \mathrm{~cm}^{-2}$ current load at $1 \mathrm{~V}$ 
Figure 1

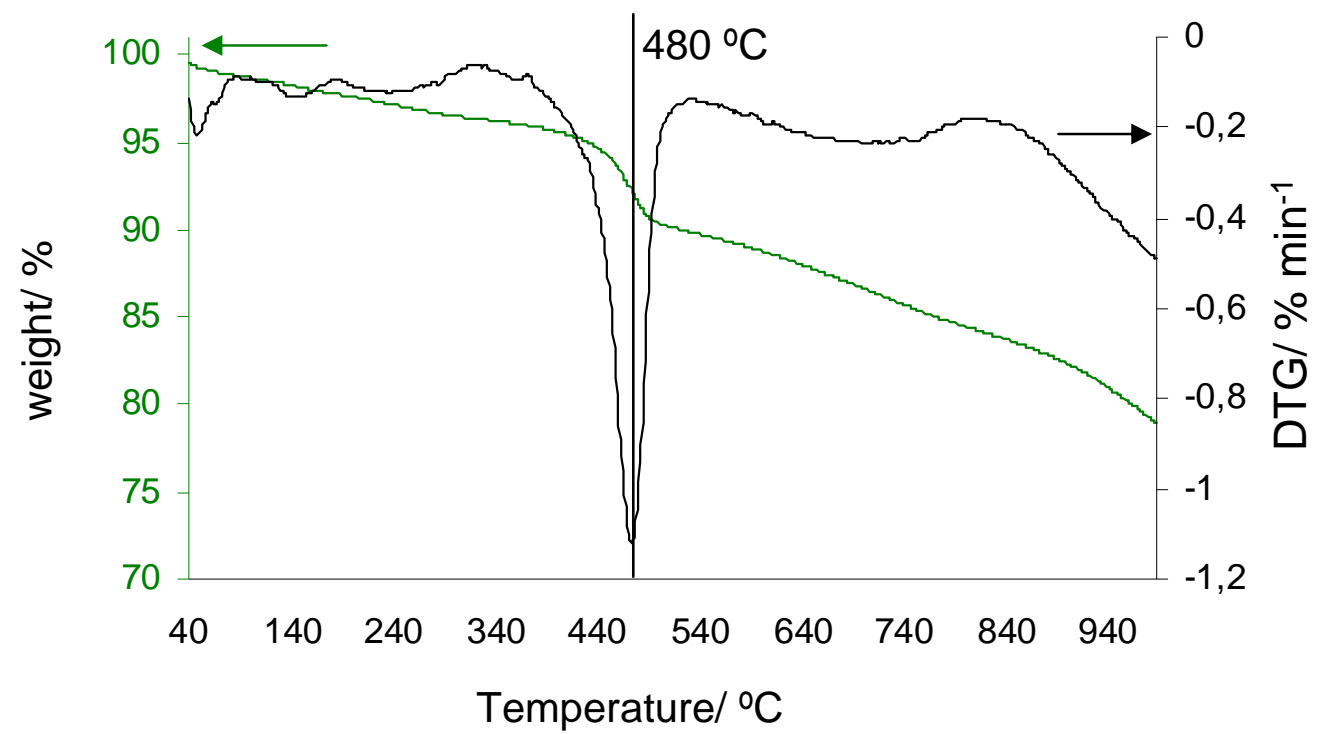


Figure 2

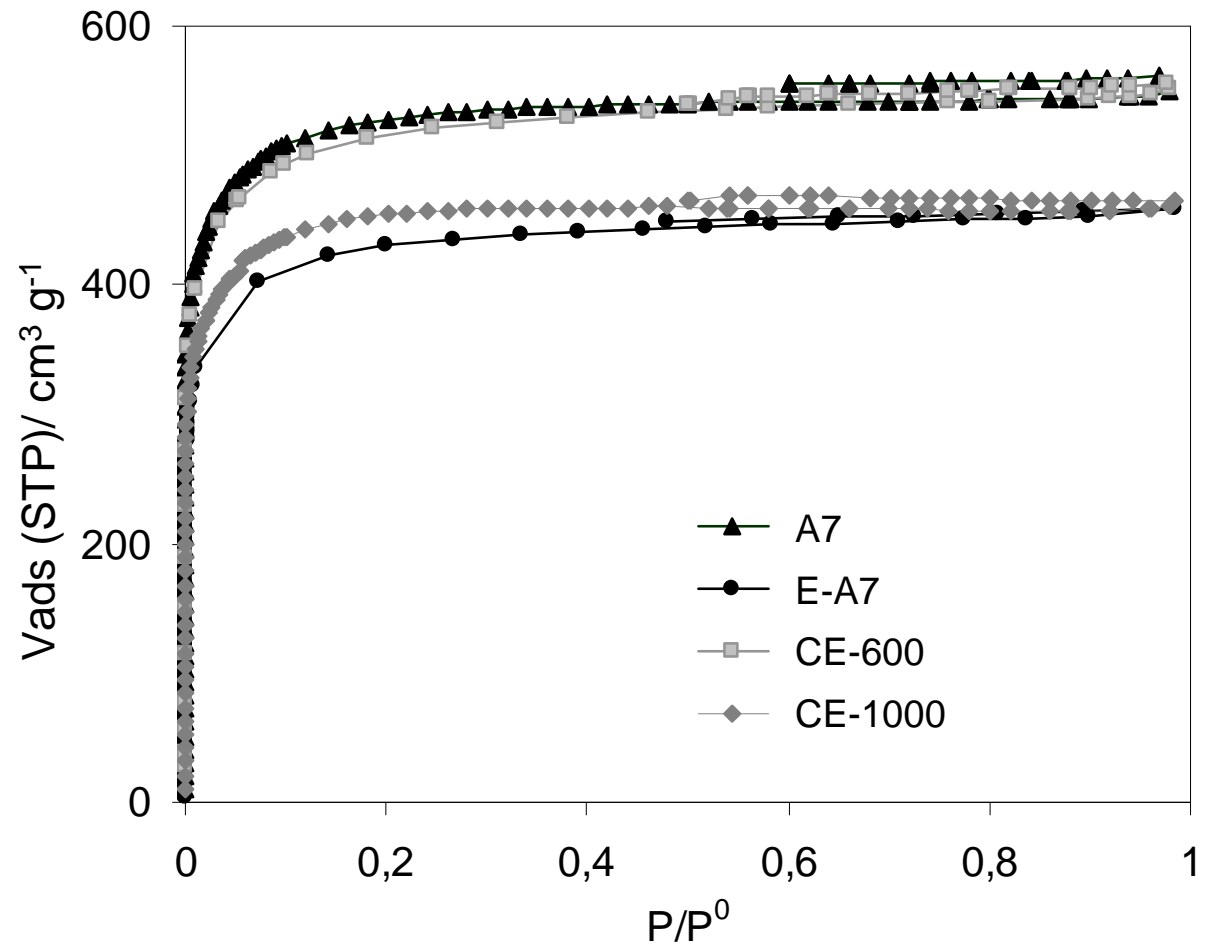


Figure 3

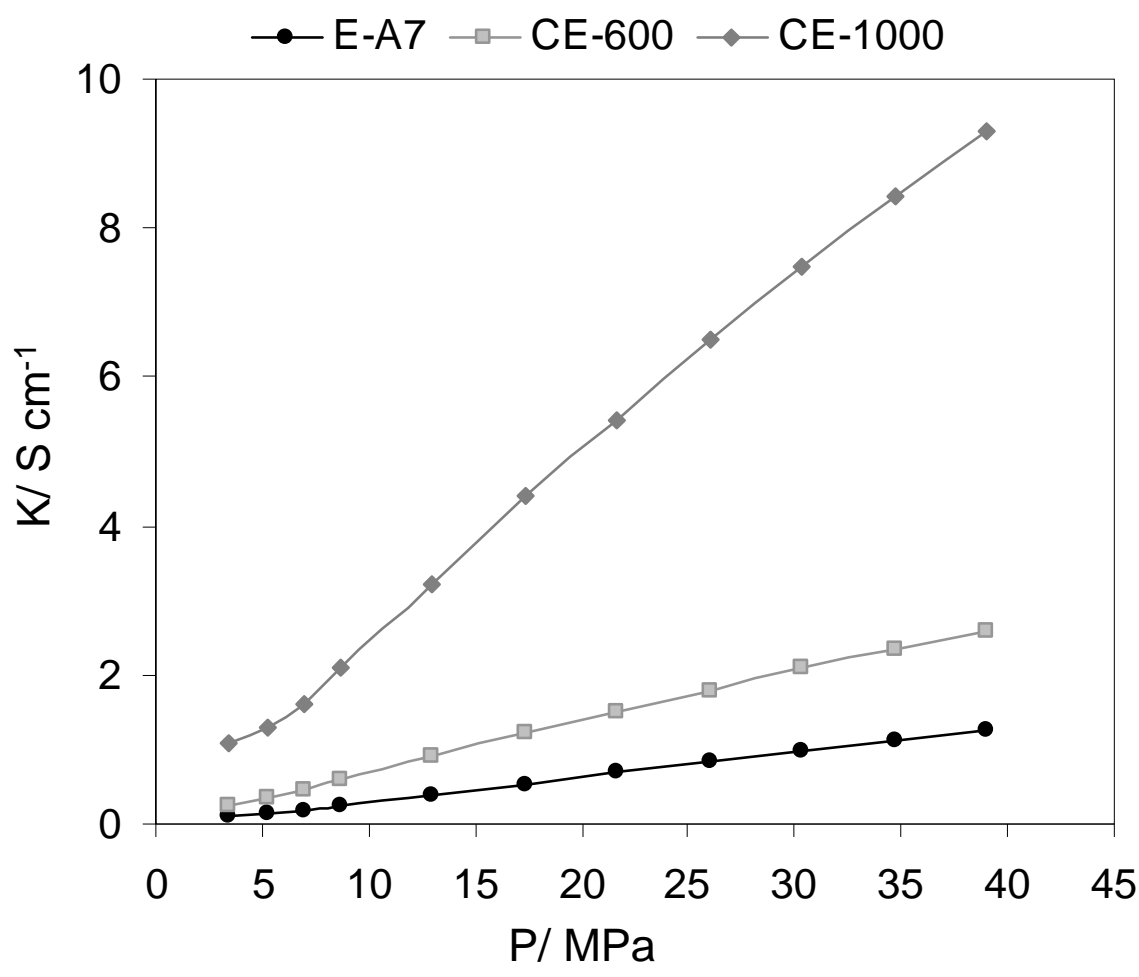


Figure 4

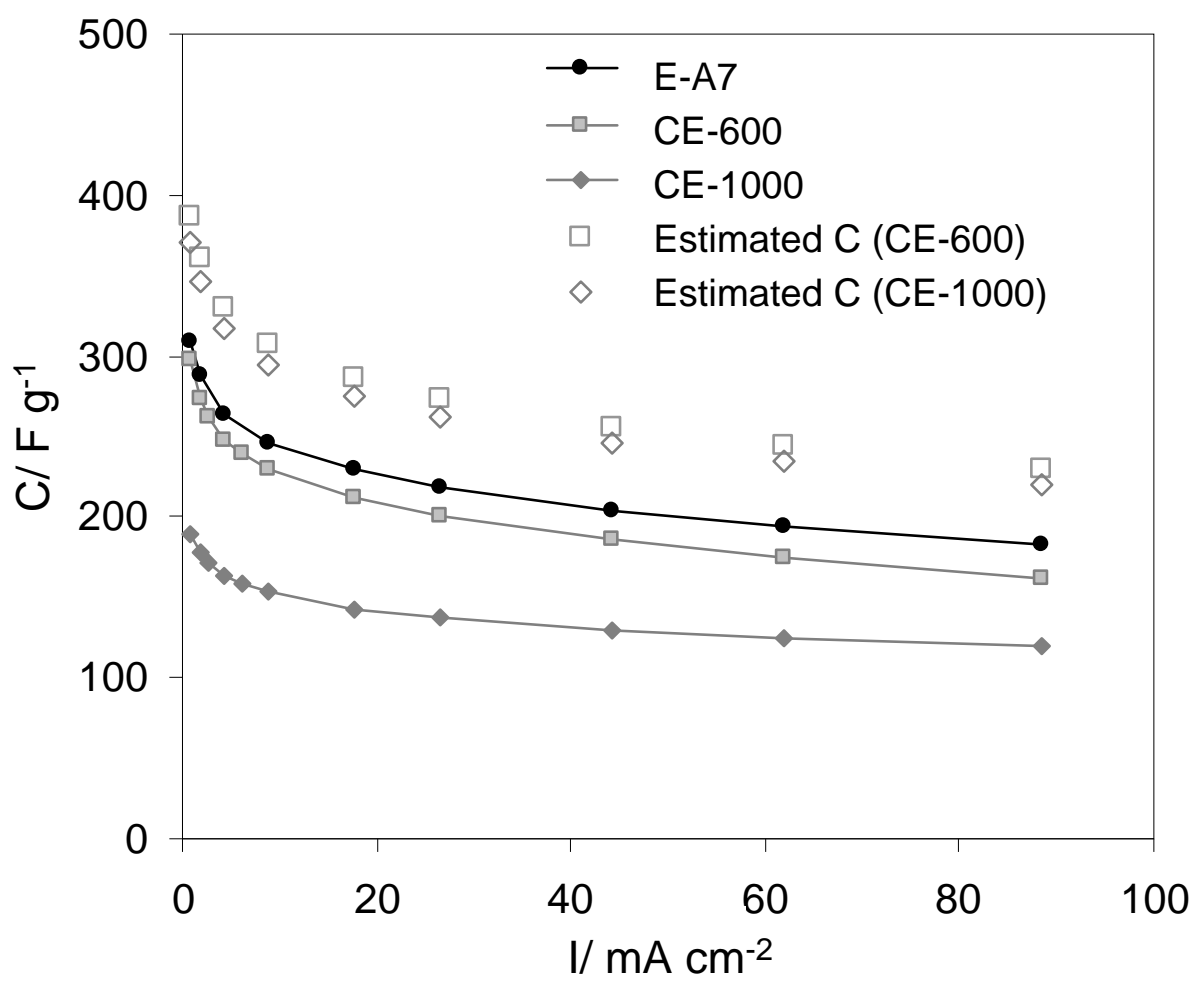


Figure 5

a)

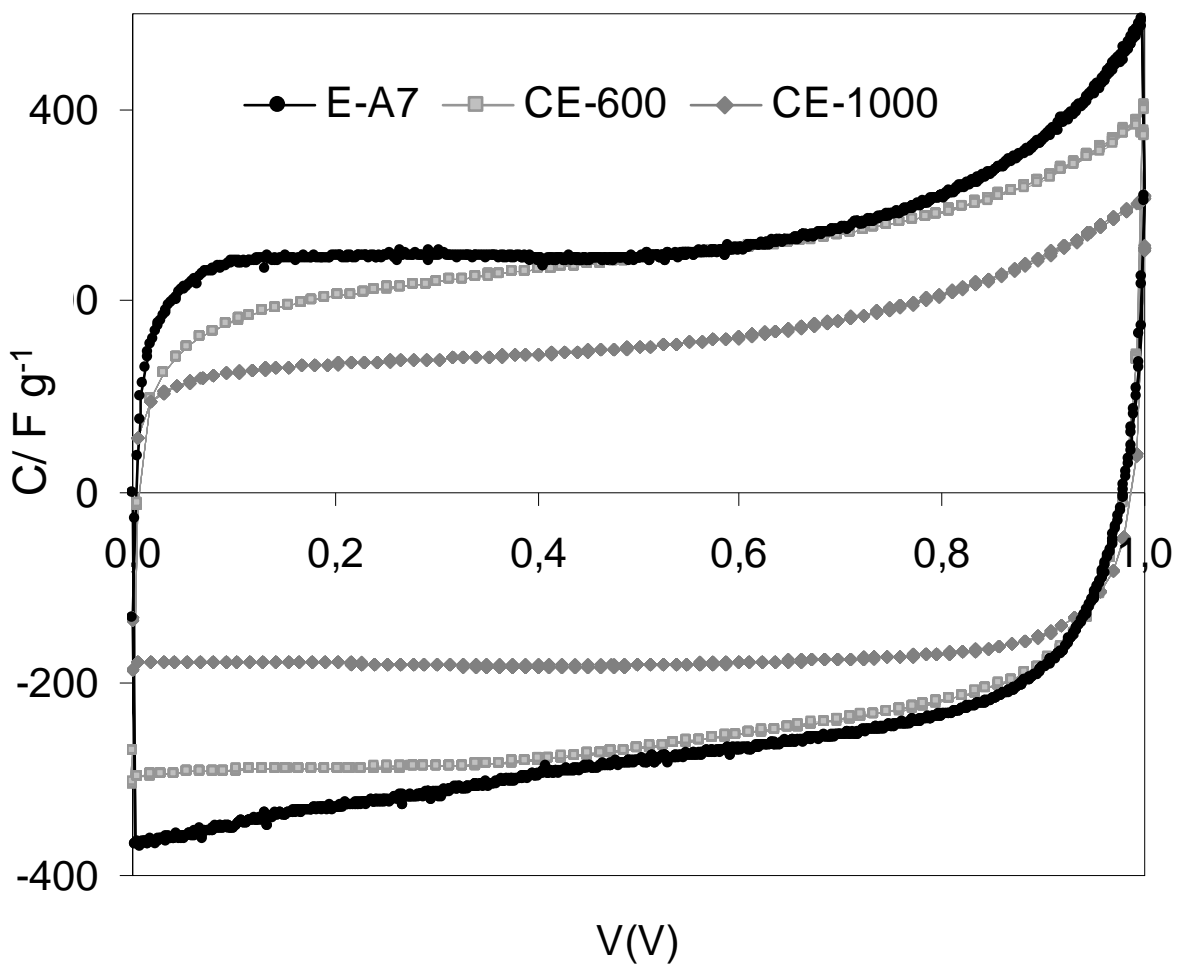

b)

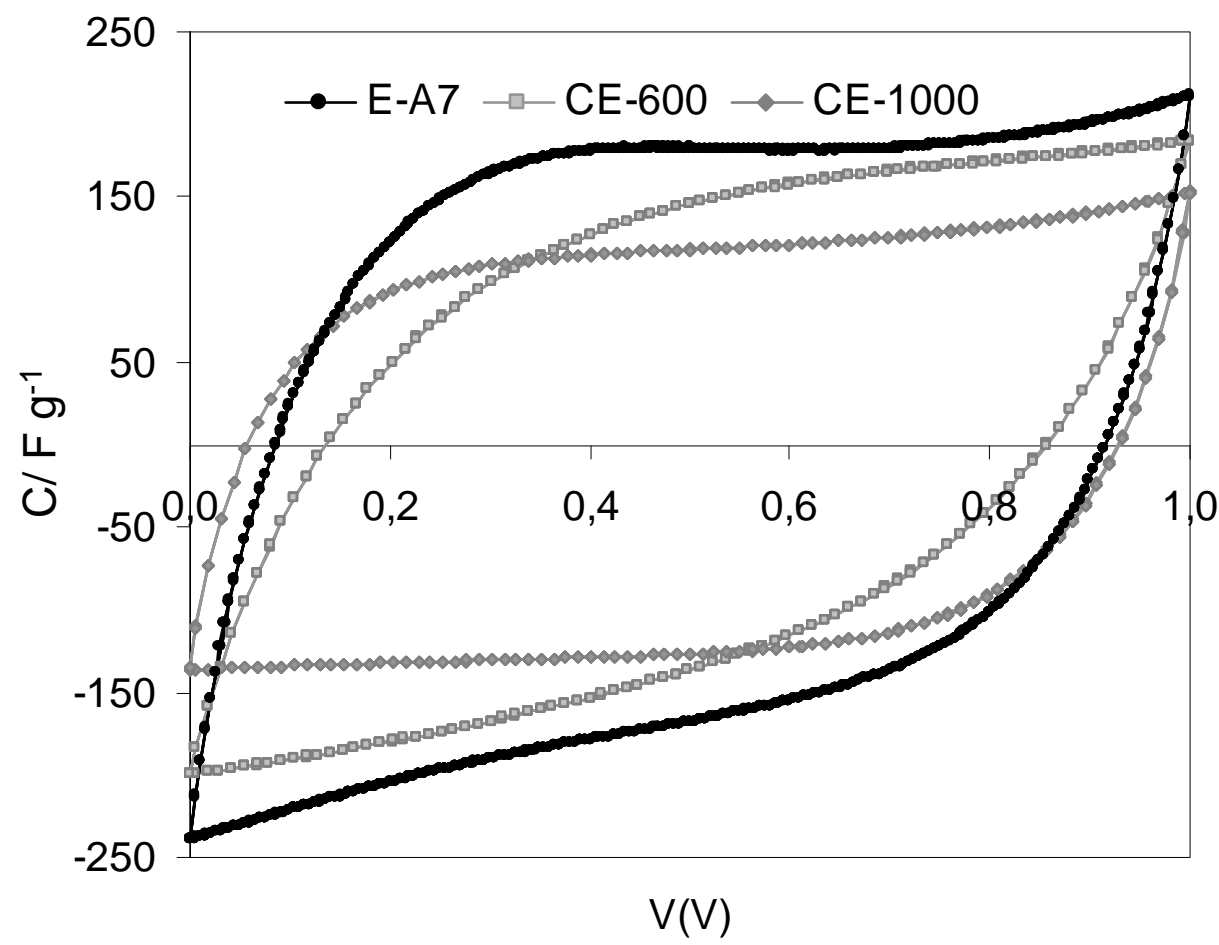


Figure 6

a)

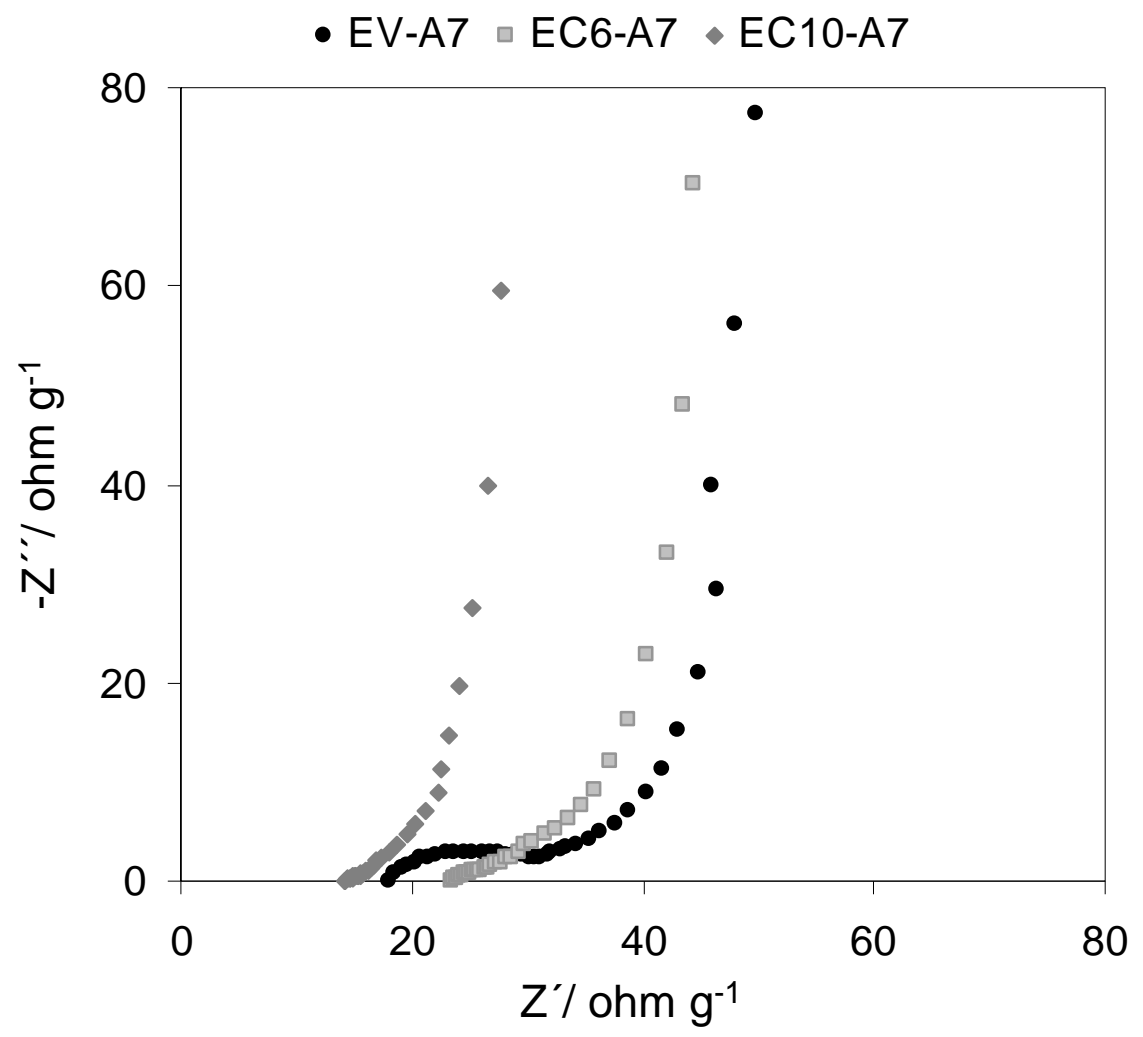

b)

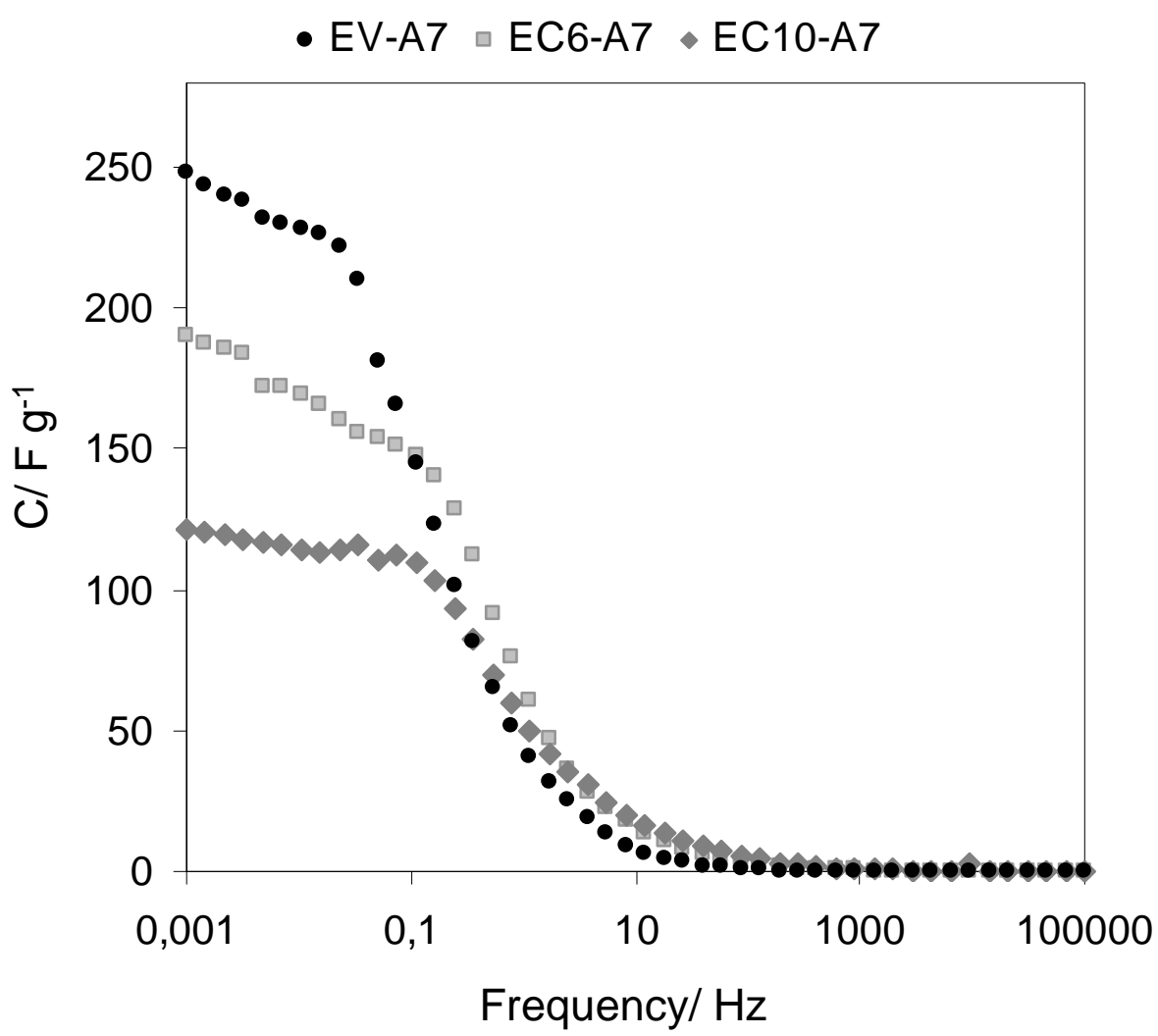


Figure 7

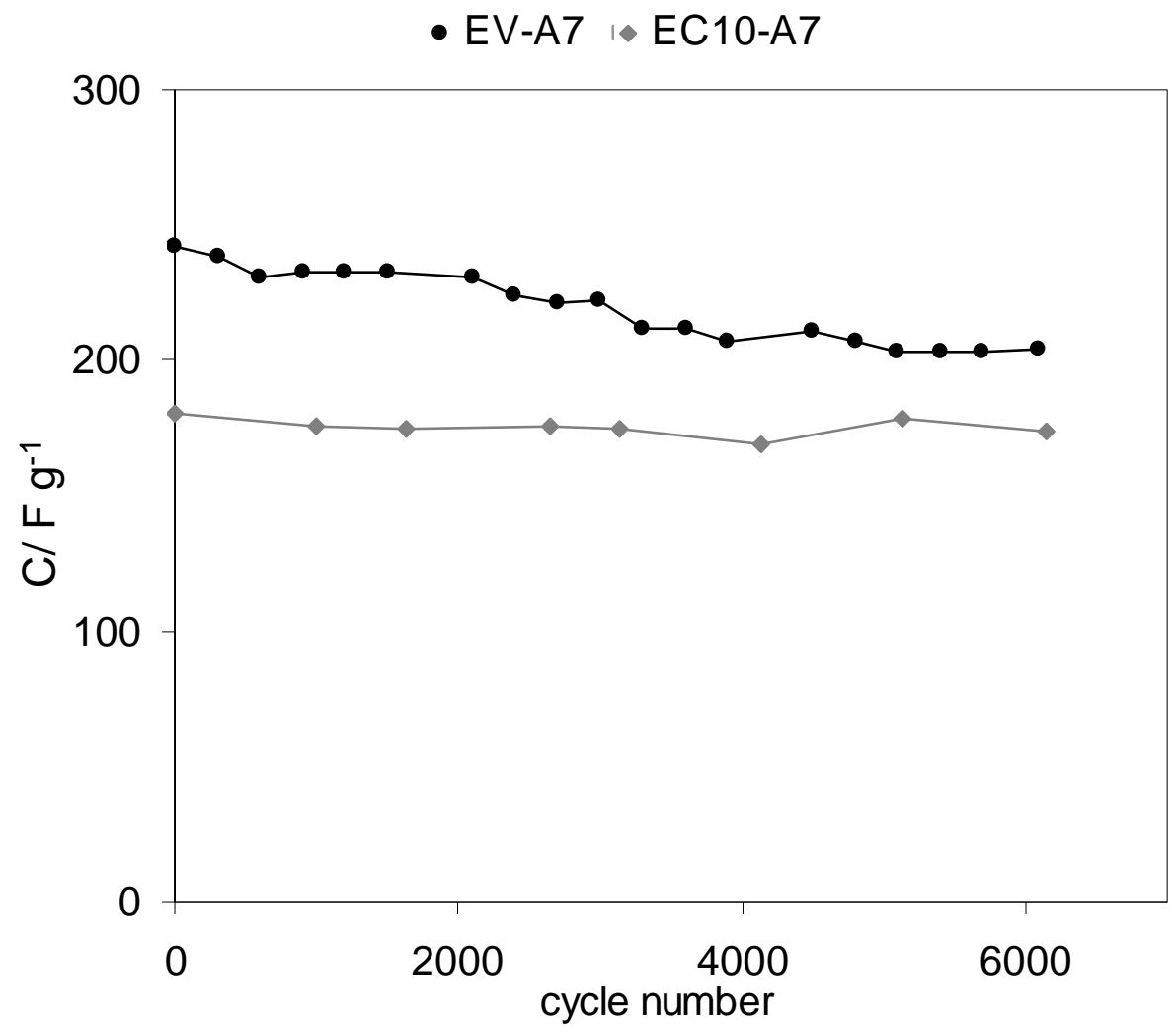




\section{TABLE CAPTIONS}

Table 1.- Textural characterization of the activated carbon and the electrodes

Table 2.- Physicochemical properties of A7, A7-600 and A7-1000

Table 3.- Heats of immersion obtained for the activated carbon and the electrodes 
Table 1

\section{$\mathrm{TPD} / \mathrm{mmol} \mathrm{g}^{-1}$}

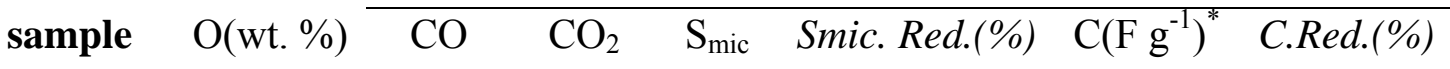

$\begin{array}{llllll}\text { A7 } & 3.5 & 1.22 & 0.23 & 1531 & 309\end{array}$

$\begin{array}{llllllll}\text { A7-600 } & 1.5 & 1.12 & 0.09 & 1407 & 8 & 285 & 8\end{array}$

$\begin{array}{llllllll}\text { A7-1000 } & 0.3 & 0.13 & 0.08 & 1318 & 14 & 196 & 36\end{array}$

*Specific capacitance values obtained from galvanostatic cycling at $0.88 \mathrm{~mA} \mathrm{~cm}$ Smic. Red. (\%), reduction of microporous surface area

C.Red.(\%), reduction of specific capacitance 
Table 2

\begin{tabular}{llllllll}
\hline sample & $\mathrm{Vt} / \mathrm{cm}^{3} \mathrm{~g}^{-1}$ & $\mathrm{~V}_{\mathrm{N} 2} / \mathrm{cm}^{3} \mathrm{~g}^{-1}$ & $\mathrm{~L}_{0} / \mathrm{nm}$ & $\mathrm{S}_{\text {mic }} / \mathrm{m}^{2} \mathrm{~g}^{-1}$ & $\mathrm{~S}_{\mathrm{BET}} / \mathrm{m}^{2} \mathrm{~g}^{-1}$ & $\mathrm{~V}_{\text {meso }} / \mathrm{cm}^{3} \mathrm{~g}^{-1}$ & $\%$ microp.
\end{tabular}

\begin{tabular}{lccccccc}
\hline A7 & 0.85 & 0.72 & 0.97 & 1531 & 2008 & 0.10 & 85 \\
E-A7 & 0.71 & 0.61 & 1.03 & 1174 & 1593 & 0.10 & 86 \\
CE-600 & 0.85 & 0.72 & 0.98 & 1467 & 1947 & 0.13 & 85 \\
CE-1000 & 0.71 & 0.62 & 0.87 & 1413 & 1591 & 0.10 & 87
\end{tabular}

$\mathrm{V}_{\mathrm{t}}$, total pore volume

$\mathrm{S}_{\mathrm{BET}}$, BET surface area

$\mathrm{V}_{\mathrm{N} 2}$, total micropore volume (DR eq.)

$\mathrm{V}_{\text {meso }}$, mesopore volume

$\mathrm{L}_{0}$, average pore diameter

$\%$ micro, microporosity percentage

$\mathrm{S}_{\text {mic }}$, microporous surface 
Table 3

\begin{tabular}{lcc}
\hline & \multicolumn{2}{c}{$-\Delta \mathrm{Hi} / \mathrm{J} \mathrm{g}^{-1}$} \\
\hline sample & $\mathrm{CH}_{2} \mathrm{Cl}_{2}$ & $\mathrm{TXP}$ \\
& $0,33 \mathrm{~nm}$ & $1,5 \mathrm{~nm}$ \\
\hline A7 & 234 & 132 \\
E-A7 & 197 & 82 \\
CE-600 & 206 & 43 \\
CE-1000 & 178 & 14 \\
\hline
\end{tabular}

